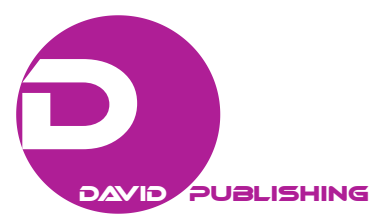

\title{
Plato Revealed: Alexander of Aphrodisias and His Philosophical Historiography
}

\author{
Raffaella Santi \\ University of Urbino Carlo Bo, Urbino, Italy
}

\begin{abstract}
Alexander of Aphrodisias's Commentary on Aristotle's Metaphysics is an important testimony to understand Plato's philosophy. In fact, Alexander uses some lost Aristotelian books, especially a work On the Good, from which we learn that Plato's metaphysics is adialectical metaphysics, founded on an original opposition of two principles that shapes the whole reality - these principles being the One and the indefinite Dyad. Sensible things participate in ideas (they receive their being from ideas) and the intermediate mathematical entities lie between these two realities. However, ideas can be traced back to ideal numbers and the principles of ideal numbers are the One and the indefinite Dyad. Thus, these principles constitute their metaphysical foundation of ideas and, through the ideas, of the whole reality.
\end{abstract}

Keywords: Alexander of Aphrodisias, Aristotle, Plato, Platonic unwritten doctrines, metaphysics, dialectic

\section{Introduction}

Alexander of Aphrodisias (on whom see Frede, 2017) dedicates to Plato half of his Commentary on Aristotle's first book of Metaphysics (Annas, 1976; Aristotle, 1984; Alexander of Aphrodisias, 1989, 2007; Brandis, 2005; Kotwick, 2016). What makes his testimony particularly interesting is that, to comment on Aristotle's statements about Plato, he resorts to three works written by Aristotle when he was still a member of the Platonic Academy, which, however, were later on lost: On the Good, On ideas and On Philosophy (see the few extant fragments in Aristotle, 1987, pp. 267-270, 333-350, 372-384, respectively) of which Alexander provides large paraphrased excerpts.

Precisely in these three subsequently lost works, used by Alexander in his commentary on the sixth and ninth chapters of Metaphysics, Aristotle expounded - though sometimes critically, as he always does (Fine, 1993; Irwin, 1988) - Plato's doctrine. The writing On the Good, in particular, is presented by the sources as a transcription of the lessons held by Plato within the Academy. Whether Alexander had the original version of this work (as of the other two) to hand or just a compendium or excerpt thereof doesn't matter, as the fact remains that he is the last commentator known to us to have read and reported some passages drawn thereof. It therefore constitutes a very important source on which it is useful to conduct an in-depth investigation (all quotations in this article are from Alexander of Aphrodisias, 1989).

As is well-known, some passages from Alexander's commentary on Metaphysics A were included among the testimonies on Plato's unwritten doctrines (Gaiser, 1998; Krämer, 1990; Reale \& Richard, 2008). Indeed, as

Raffaella Santi, Dr., associate professor of History of Philosophy, Department of Humanities, University of Urbino Carlo Bo, Urbino, Italy. 
we shall see further below, they attribute to Plato, based on Aristotle's work, some conceptions that do not find an immediate confirmation in the dialogues, which is why this and other testimonies gave rise to an intense debate among Plato's interpreters, who are substantially divided into two factions, namely between those who give credit to the testimonies of the indirect tradition and those who, on the other hand, reject the latter or, in any case, minimise their value (Gaiser, 1968; Findlay, 1974; Reale, 1997; for a divergent interpretation of Alexander's testimony, see Berti, 1994, 1997; Isnardi-Parente, 1995, 2000).

As is usual for his method, in his Commentary on the first book of Metaphysics too, Alexander examines Aristotle's statements in the way they follow one another in the original text, and comments on them with the aim of explaining their meaning. In doing this, not only does he stick to the Aristotelian text, but he also resorts, on his own initiative, to other works by the Stagiriteauthor that he deems particularly interesting in order to understand certain passages of the Metaphysics. The latter also include precisely those already mentioned above (that we no longer have at our disposal), of which Alexander quotes or, to be more precise, rewords some excerpts he deems useful for the sake of explaining the meaning of the passages he is commenting on.

As a rule, he follows the Aristotelian discourse and abides by the contents it expresses, which he explains extending them only when he believes that their meaning is not sufficiently clear. Even the language he adopts is faithfully Aristotelian. Actually, he uses interpretative schemes and technical terms from the Aristotelian philosophy, which should also be taken into account when, as in the case on hand, we try to reconstruct the Platonic doctrine that emerges from his testimony. Likewise, we should not lose sight of the general context within which the approach to the Platonic doctrine takes its place as part of the Aristotelian discourse that Alexander resumes and comments on.

In the first book of Metaphysics, Aristotle actually wants to demonstrate dialectically, i.e. resorting to common opinions (especially those of scholars), that wisdom is the knowledge of the primary causes and of the first principles of reality, and that these first primary causes or first principles belong exactly to four kinds, namely: formal, material, efficient and final (as he had already argued in the second book of Physics). To do this, he shows that all the other philosophers who dealt with the principles conceived, even partially or in any case with some gaps or misunderstandings of various types, precisely the four kinds of cause that he believes to be true. Among these philosophers we find Plato. In the sixth chapter, Aristotle expounds his doctrine, highlighting how he sought and identified two first principles of reality: the One and the indefinite Dyad, which correspond to its formal and material causes, respectively. The ninth chapter contains a critique of some Platonic conceptions of the nature of ideas, numbers and principles, with a series of arguments expressed in an extremely concise manner.

In these two chapters, the text of Metaphysics appears very concise and contracted, given that the themes dealt therein were already covered in the previous works, whose content was certainly known within the academic and Aristotelian circuit; which is why Aristotle did not feel the need to further develop such themes again, confining himself to briefly referring thereto instead. Therefore, given his extreme conciseness in tackling such themes, Alexander feels the need to expand his information: he explains the Aristotelian statements by resorting to the work On the Good for the sixth chapter and to On Ideas and On Philosophy for the ninth chapter.

\section{Ideas, Mathematical Entities and Sensible Things}

At the beginning of his commentary on A6, Alexander points out that Aristotle, when he begins to deal with Plato's doctrine, immediately emphasises not only its points of contact with the Pythagorean doctrine he 
has been speaking about shortly before (in the fifth chapter), but also the features he considers completely original, including the theory of ideas (Alexander of Aphrodisias, 1989, p. 77).

But what led Plato to set out the ideas? The influence (as Alexander explains following Aristotle) of the Heraclitean and Socratic conceptions, seeing that, by accepting the Heraclitean vision according to which all sensible things are constantly moving and changing, but also in view of continuing the Socratic search for the universal, i.e. believing that it must be possible to define the entities and therefore to achieve a certain knowledge, Plato goes as far as to assume that the definitions should apply to entities other than the sensible ones, to natures that are beyond the sensible things and that provide them with their being and name: the ideas, which constitute the ontological foundation of all sensible things. But what kind of link exists between these "natures that are beyond the sensible things", the ideas, and the sensible things themselves? And what does it mean that the sensible things receive their being and their name from ideas? The answer hereto lies in participation (métexis). At this point, Alexander illustrates this phrase of Aristotle: "indeed, the many entities that are synonymous with forms exist by participation in them". According to Plato, participation is the sharing of essential characters. A thing participates in an idea when it can be defined through that idea, which expresses in a perfect and stable way those characteristics that the thing possesses only in an imperfect and unstable way.

Thus, there are two different kinds of reality, namely a sensible reality and an intelligible reality. For Plato, the definitions, as Alexander explains, refer in the proper sense only to the second kind of reality and in a derivative sense to the first, which exists by participation. According to Aristotle, however, Plato, who did nothing but call "participation" what the Pythagoreans referred to as "imitation" (mimesis), did not clarify the mechanism of participation (Alexander of Aphrodisias, 1989, pp. 78-79). Alexander disagrees and refers to the Parmenides: "[...] although this point does seem to be clarified by Plato in the Parmenides" (Alexander of Aphrodisias, 1989, p. 79).

Actually, in this dialogue Plato thematises the participation relationship, but in an aporetic way (Plato, 1997, pp. 364-365). Parmenides questions the young Socrates on the assumption of the existence of ideas "in which all other realities participate and from which they derive their name". However, if the scheme of the relationship between the whole and the parts that describes the physical reality is applied to participation, it is not possible to get rid of the aporia for which a thing must participate either of the whole idea or of a part thereof, since none of the two assumptions is acceptable - due to the fact that they both give rise to absurd consequences that seem to make participation impossible. However, further on in the dialogue Plato suggests the answer to this problem (Plato, 1997, pp. 365-366). The aporia relating to the whole and the parts can be overcome if we consider that, from a conceptual point of view, the whole is not merely a sum of parts, but the idea that gives unity to the parts without being contained therein. This giving meaning and consistency to the parts, which also means founding them ontologically, is a function of the whole that does not affect its nature, whereupon it remains undivided and indivisible in itself (Plato, 1997, pp. 378-379). This is thus how participation - as wished by Alexander - is explained.

Nonetheless, between ideas and sensible things, Alexander writes again by drawing on the Aristotelian terms, Plato identified (a conception that is not found explicitly thematised in the dialogues) another kind of reality: that of mathematical entities, which thus come to occupy an intermediate position (metaxu), because they are eternal and absolutely immobile like ideas, but at the same time multiple like the sensible things.

Whether mathematical entities derive from the sensible things by abstraction and are therefore properties inherent to the sensible things considered as separate, is a matter covered by the Aristotelian doctrine. 
Alexander claims that the truth could be this, although he adds that Plato did not state this, turning such entities into independent and eternal natures and substances. There is no causal relationship, therefore, between the sensible things and the mathematical entities starting from the former: the mathematical entities do not derive by abstraction from the sensible ones; on the contrary, it is the mathematical entities that give the sensible phenomena that arithmo-geometric consistency that allows them to come very close to the perfection of ideas, without ever reaching it.

From these first two parts of the commentary it can therefore be inferred that Plato thought of reality as a structure hierarchically organised on three ontological levels, the higher of which founds, that is, confers being on the lower one, according to the following scheme: ideas $\Rightarrow$ intermediate mathematical entities $\Rightarrow$ sensible things.

\section{The Theory of Principles}

Further on in Alexander's commentary, another theory is outlined which does not find a precise confirmation in the Platonic dialogues, according to which the ideas themselves would be founded on something else (this is Plato's theory of principles).

According to Plato, ideas cause everything, so that if there are principles of ideas, these will also be principles of all other things. This is the doctrine that Aristotle now attributes to Plato, claiming that as principles of ideas, and therefore as principles of everything, he placed the One on one side and the Great and the Small (referred to jointly as the indefinite Dyad) on the other, corresponding to the formal cause and to the material one, respectively (Alexander of Aphrodisias, 1989, pp. 80-82).

Now, what is the mechanism that leads from principles to ideas? By participating in the One, the Great and the Small, by nature undefined, receive a certain shape, thus giving rise to ideas, which are also numbers, though not mathematical but "ideal" (eidetikos) ones. Alexander points out that these ideas, which originate immediately from the principles, should not be confused with the "other" forms, just as numbers should not be confused with the "other" numbers, which are most likely_-given that Alexander has referred thereto just a little earlier - to be the intermediate mathematical numbers. The more difficult thing to achieve is to identify which ideas are also numbers, ideal numbers, and to understand in what sense they are so.

In reality, for Plato the ideas are not numbers: they are traceable back to numbers as they are translatable into numerical ratios.

To explain this, we can refer to a passage to be found about many pages ahead of the one just mentioned, in which Alexander takes up an argument through which Aristotle, in A9, wants to demonstrate that it is impossible for ideas to be at the same time numbers and causes of the sensible things. This, Alexander explains, is impossible even if we consider the sensible things as certain numerical ratios-as can be seen, for example, through harmony, which is not a number, but a certain ratio among numbers. Harmony is identified with sounds, which constitute its matter, and varies according to the different relationship that is established among them, and this is its form: "But if this is the case, the Ideas too, since they are models (paradeigma) of these things [sensible things], will themselves have to be numerical ratios and not simply numbers" (Alexander of Aphrodisias, 1989, p. 149). The argument ends as follows: it is not possible for a number to be the cause of what is numerically related; therefore, if ideas are numbers, they cannot be the causes of sensible things, so they are not numbers (also because otherwise they would be compound and not simple). Therefore, ideas are not numbers in themselves; moreover, if they are not numbers, they are not numerical ratios either. This is the Aristotelian argument resumed by Alexander. 
Indeed, according to Plato, while remaining (when considered in themselves) uniform and monoeidetic, ideas are structured precisely according to numerical ratios which determine their greater or lesser universality. Especially from Phaedrus and Philebus, in fact, it can be inferred that knowing ideas means knowing how to grasp their internal articulation, enumerating the multiple forms that make them up, in order to establish how many they are or better to establish their total number, which, in Plato's opinion, is intermediate between Infinity and the One. Even the diairetic and synoptic processes on the basis of which ideas can be divided and reunited, as can be seen above all from the examples of the Statesman and of the Sophist, are made possible by the composite structure of ideas - which, however, if considered in themselves remain uniform.

But now let us go back to the passage in which Alexander names the principles and the ideas-numbers. Here he no longer goes further but, following Aristotle's discourse, dwells on the analogies and differences existing between Plato and the Pythagoreans.

Speaking of Plato, Aristotle insists on the relations of his doctrine with the Pythagorean one. In particular, for him Plato agrees with the Pythagoreans in believing that the One is substance (ousia), obviously in the Aristotelian sense, i.e. something that is not predicated upon any substratum, but upon which all the rest is predicated instead. So, like the Pythagoreans, Plato thought that the One was substance and that numbers were the causes of entities, although he considered these causes as separate from the consequences, contrary to what the former did. But Plato stood up significantly from the Pythagoreans for having conceived, within his theory of principles, a second principle in addition to the One, playing the role of material cause, the indefinite Dyad, and for having separated numbers from sensible things, while the Pythagoreans placed the unlimited in the one - because the one is even-odd and, therefore, as odd it is limited, while as even it is unlimited - and thought that one and the other numbers were the material cause of entities (Alexander of Aphrodisias, 1989, p. $82)$.

In short, the analogies and differences between Plato and the Pythagoreans remarked by Alexander on the basis of Aristotle are as follows: for both, the One is substance but, while for the Pythagoreans numbers are the immanent causes of entities, i.e. the material constituents of entities, for Plato they are the paradigmatic causes of entities and, while for them numbers coincide with sensible things, for Plato they are separate therefrom and, precisely, they are intermediate between the sensible things and the ideas. Moreover, for the Pythagoreans the One is the principle of numbers and is both limit and unlimited, while for Plato the One is the limit, while the unlimited lies in the second principle: the indefinite Dyad made up of great and small, excess and defect.

There is no ambiguity in the reference to Plato and the Pythagoreans; on the contrary, what Alexander highlights are above all the differences between them; and the underlying reason why Plato differed from the latter should be found in his dialectical speculation.

Aristotle states that it is precisely dialectic as an "investigation into notions" that makes the difference between Plato and the Pythagoreans (Alexander of Aphrodisias, 1989, p. 82). In Plato, therefore, according to Alexander, dialectic - meant as a search for definitions and diairesis of intelligible categories and species - coexist with dialectic - meant as an analysis of the sensible things which resolves them into principles and non-sensible elements.

As for dialectic as a division of ideas and a search for definitions, we find it operating in the Platonic dialogues (just think, for instance, of the Sophist). On the other hand, the dialectic that brings back sensible things to the immaterial principles (that constitute their own elements) is not explained in the dialogues.

We can find some hints in the Phaedrus, in the Symposium and in the Republic. Especially in the 
Parmenides Plato gives us a hint of the nature of the relationship of participation between sensible things and ideas; moreover, in the same dialogue he provides an example of the dialectical investigation that leads to the first principles and which had been announced in the Phaedo. However, in the Parmenides too he fails to explicitly thematise the configuration of the relationship existing between ideas and ideal numbers and between these and the first principles. Even the Philebus, which, however, illustrates the four highest categories of Limit, Unlimited, Mixture and Cause of the mixture, does not fully explain the ontodialectic mechanism whereby the principles relate to the principates and vice versa, and the same goes for the Timaeus, where the second principle also appears as kora.

An explanation for all this can be found in the testimonies of the indirect tradition, the most important of which are the Aristotelian ones.

\section{Understanding Plato Through Aristotle's Lost Work On the Good}

It should bereminded that Aristotlehad transcribed the Platonic lessons relating to these subjects in his three books On the Good. Thus, after illustrating what, according to Plato, constitutes the ontological structure of reality and what its first principles are, Alexander now draws widely on this Aristotelian work with the aim of explaining Plato's assumption of the first principles.

Plato and the Pythagoreans came to the conclusion that numbers are the principles of entities, as they originated in turn from what is primary and non-compound (Alexander of Aphrodisias, 1989, p. 83).

The assumption of numbers as principles of the entities - as non-primary, that is, non-absolute, principles, but derived from other principles - is justified by reasoning applied to pure geometry. It is a dimensional reduction based on the assumption that it is the logically prior element that makes the subsequent one thinkable, according to a foundation that is logical and ontological at the same time.

Alexander reports that what comes first of bodies (which have three dimensions, namely: length, width, and depth) are the surfaces (which have two dimensions, namely: length and width), and which what comes first of the latter are the lines (which have only one dimension: length); however, lines are ultimately made of points, which mathematicians call signs and which Plato and the Pythagoreans refer to as units (monaden); but the units, which come before all the rest, are numbers, thus numbers come first among all entities. This is how the argument comes to an end: but ideas, which come first with respect to things, are numbers and therefore the principles of numbers are also the principles of ideas, and the One is the principle of everything.

It is obvious that here Alexander is referring only to Plato, since he uses the verb in the third person singular and since the Pythagoreans could not possibly speak of ideas, due to the fact that they did not know dialectic. Immediately afterwards, he dwells again on what in Plato's opinion are the first principles of reality (Alexander of Aphrodisias, 1989, p. 84).

Now, why are the principles of numbers and ideas, and consequently of all other entities, precisely Unit and Duality?

Taking them from the writing On the Good, Alexander provides what Enrico Berti called "three justifications of the principles", i.e. three arguments that explain why-according to Plato-it is necessary to consider precisely the One and the indefinite Dyad as the first principles of all entities (Berti, 1997, pp. 207-221).

The first justification can be summarised in these terms (Alexander of Aphrodisias, 1989, p. 85). Numbers, just like the rest of entities, have a mixed structure; in other words, they are made up of unit and multiplicity. 
Actually, in numbers there is the One and what is beyond the One, namely the many and the few. On the other hand, the principle of the many and few is Duality (the indefinite Dyad), because it comes first beyond the One. Duality is indeed conceptually divisible: it can be considered as what is double-in which sense it is the principle of growth - and as what is half - in which other sense it is the principle of diminution - and thus includes both the much and the little. The One, on the contrary, is indivisible, so that Duality, which is divisible, is opposite to the One.

The second argument is this: of all that is, both of the self-subsisting entities and of the opposites, the principles are the Equal and the Unequal, attributable to the One and to the indefinite Dyad, respectively. The indefinite Dyad is actually composed of the great and the small, which are what is by excess and what is by default, and therefore it is the Unequal par excellence, while the One is the Equal par excellence. Here it is a matter of bringing all entities, both self-subsisting and opposite, to the two principles, which in this case act as very general categories to which every general idea - and therefore every other entity, given that it receives being from ideas - can be traced back. As each entity has in itself unit and multiplicity, it shows both principles, but, in self-subsisting entities, equality, identity with itself and unit prevail, while in opposing entities, such as good and evil, inequality and opposition prevail, which manifest themselves exemplarily in the excess and defect of the indefinite Dyad.

No sooner is the indefinite Dyad (we have thus moved on to the third argument: determined and delimited by the One-which brings measure between excess and defect - than it becomes number two, obviously the ideal number, duality, as it takes on a monoeidetic configuration. It constitutes the first number, whose underlying principles are the excess and the exceeded determined by the One as double and half. We thus transition from the indeterminate Duality, the principle of indefiniteness, to the determined duality, ideal and monoeidetic. What generates determination is the nature of the One, since each thing is one, as it is something defined and determined (Alexander of Aphrodisias, 1989, p. 85).

In fact, once it has been demonstrated that the One and the indefinite Dyad are principles of numbers and ideas, it follows that they are also principles of everything else. Here precisely, Alexander showed that Plato had reached this demonstration: through the dimensional reduction he had proven that everything can be reduced to a number and then, through the first and third arguments in support of the principles, that the first principles of reality are the One and the indefinite Duality, precisely because ideal numbers are generated from them; with the second argument he had proved that the principles are precisely those two because all ideal entities can be traced back to them, both for the self-subsisting entities and for the opposites.

Now Alexander moves on to explain in more detail how numbers are generated starting from principles. Aristotle attributes to Plato the theory according to which all numbers except the prime ones are born from the Dyad, as from a receptacle, and Alexander comments that the Dyad has indeed the ability to divide everything, that is why it is called "producer of the two". The division into two performed by the Dyad coincides with the generation of numbers. Actually, the Dyad, acting as if it were a receptacle, a matrix or a seal, turns everything whereto it applies into two or double. In so doing, it produces numbers, although only after undergoing in turn the delimiting action exercised by the One, which, as Alexander previously stated, determines the excess and defect of the Dyad as double and half, i.e. gives the Dyad, otherwise undefined, unlimited in its two opposing tendencies, a precise and defined form - further on Alexander will define the One as a "producer of form".

The Dyad, thus determined by the One, produces numbers, but only even numbers, because its function is to duplicate or divide by two, since it is configured as double and half. Thus Alexander interprets the 
Aristotelian expression that reads "produces all numbers except from the prime ones" in the sense that it produces all numbers except the "odd" ones, because for the latter-which are "prime" because they come before the even ones - a unit overlapping even numbers is needed.

It should be borne in mind that here Alexander is not referring to intermediate arithmetic numbers, which are arranged in an infinite set, but to ideal ones. Actually, he names the numbers up to nine and does not go beyond, and we know from Aristotle that according to Plato the ideal numbers only reach the Decade, although - according to Aristotle - for Plato they cannot be combined, which seems to clash with Alexander's explanation, according to which, given the unit (not the One as principle but the ideal unit) from which they originate - or "are measured", as Alexander says - the odd numbers, the Dyad, "applying to the One turned the latter into a two (indeed, two times one makes two); applying to the two, turned the latter into four (indeed, two times two makes four) and similarly turned the three into six, and the same goes for the other numbers". Konrad Gaiser believes that "here Alexander no longer relies so much on the Aristotelian 'transcription', as he follows instead a less authentic source". Whether or not this is so, it should be borne in mind that Alexander is not talking about repeatable operations of an arithmetic nature, but about the ontogenetic process that gives rise to ideal numbers, in the sense that he founds them metaphysically; once produced, they, in turn, remain indivisible in themselves and non-processable. Another difficulty lies in the fact that the Dyad intervenes only in the generation of the "even" ideal numbers and not also in that of the "odd" ones, which seems to be also confirmed further on in the commentary.

Here, however, it is stated that the Dyad produces not only all even numbers, but also multiplicity in general: it is a "generator of multiplicity"; while the One is a "unit producer". Therefore, the Dyad is to all intents and purposes the principle of the multiplicity of entities, which is opposed to the One, as principle of unit.

According to Aristotle, Plato resorted to only two types of case, namely: formal and material. Alexander comments that Plato conceived the One as a formal principle-which gives form to ideas, which in turn transmit it to sensible things - and the indefinite Dyad as a material principle (Alexander of Aphrodisias, 1989, p. 90).

We are in the presence of a characterisation of the Platonic principles in the sense of the Aristotelian causes, since the indefinite Dyad is seen as a material substrate and the One as a formal principle that applies to matter. Then there is a reflection by Alexander, who thinks that Plato also spoke about the efficient cause and of the final cause (Alexander of Aphrodisias, 1989, p. 91).

Plato therefore, at least according to Aristotle's report, did not tackle in his lessons the causes that in Aristotelian language are called efficient and final, respectively. On the contrary, again according to Aristotle, Plato also assigned to the two principles he admitted the axiological value of causes of good and evil, and at this point it is not clear whether it is still a doctrine resumed and expounded in the written On the Good or not: the title of the work, however, would suggest it is quite so. Here is the reason for this assignment (Alexander of Aphrodisias, 1989, p. 92).

\section{Conclusion}

If we take into account the fact that Alexander, while writing his commentary on Metaphysics A6, had before his eyes, if not precisely the original text, at least a reliable compendium of the writing On the Good, from which he most likely drew the whole series of information he reports, that is not to be found either in the 
Platonic dialogues or in Metaphysics A6, we might be led to think, in a completely hypothetical way, that in his commentary he was inspired by the Aristotelian discourse, and before that to the Platonic discourse that emerges from the work On the Good and, whose pattern he would have even followed.

If this were true, it could be deduced that the three books of the lost work had a physiognomy of this type: the first book outlined the ontological structure of reality, of which it showed the first principles, that is to say, it explained, as we have seen, the relationship of participation between sensible things and ideas, the intermediate role of the mathematical entities, the reduction of ideas to numbers and the main function of the One and of the indefinite Dyad; the second book focused on Plato's analogy-differentiation relationship with respect to the Pythagoreans, from whom he had certainly drawn the essential elements, above all for his philosophy of mathematics, but from whom he had also significantly diverged thanks to his innovative dialectic investigations, with all the consequences they entailed; finally, the third book demonstrated the need to lay the foundations of reality identified in the principles with a series of arguments and explained the mechanism of dimensional reduction, which corresponds to a simplifying logic - that of categorical reduction-implying a generalising logic and the production of the first principates, ideal numbers, from the principles. This is a hypothetical scheme of On the Good that can be inferred from Alexander's commentary on Aristotle's Metaphysics A6.

In the light of the analysis offered by Alexander's testimony, Plato's metaphysics emerges as dialectical metaphysics, founded on an original opposition of two principles that shapes the whole reality (Reale, 1997).

Sensible things participate in ideas (i.e. they receive their being from ideas) and the intermediate mathematical entities lie between these two realities. However, ideas can be traced back to ideal numbers and the principles of ideal numbers are the One and the indefinite Dyad. Such are the principles, also because every self-subsisting reality can be traced back to the One as to the absolutely Equal, while every reality opposing another can be traced back to the indefinite Dyad as to the absolutely Unequal.

The ideas, which for Plato are the Being in the proper sense and the exclusive object of dialectic, originate from the first principles, the One and the indefinite Dyad, which therefore constitute their metaphysical foundation.

\section{References}

Alexander of Aphrodisias. (1989). On Aristotle Metaphysics 1. (W. E. Dooley SJ, Trans., with an Introduction by R. Sorabji \& R. W. Sharples). London: Bloomsbury.

Alexander of Aphrodisias. (2007). Commentario alla Metafisica di Aristotele (Unabridged Italian translation with parallel Greek text). G. Movia, (Ed.). Milan: Bompiani.

Annas, J. E. (1976). Aristotle's Metaphysics, Books M and N, translated with introduction and notes. Oxford: Clarendon Press.

Aristotle. (1984). Metaphysics. In J. Barnes (Ed.), The complete works of Aristotle. The revised Oxford translation (Vol. 2, pp. 1552-1728). Princeton: Princeton University Press.

Aristotle. (1987). Aristotelis Opera. Vol. 3: Librorum deperditorum fragmenta. O. Gigon, (Ed.). Berlin-New York: Walter de Gruyter. Berti, E. (1997). La filosofia del "primo” Aristotele. Milan: Vita e Pensiero.

Berti, E. (1994). Le dottrine non scritte "Intorno al bene" nelle testimonianze di Aristotele. In G. Reale (Ed.), Verso una nuova immagine di Platone (pp. 251-294). Milan: Vita e Pensiero.

Brandis, C. A. (2005). A study of the lost books of Aristotle On the Ideas and On the Good or On Philosophy. O. F. Summerell, (Ed.). Frankfurt am Main: Peter Lang.

Findlay, J. N. (1974). Plato. The written and unwritten doctrines. Abington-New York: Routledge.

Fine, G. (1993). On ideas: Aristotle's criticism of Plato's theory of forms. Oxford: Clarendon Press.

Frede, D. (2017). Alexander of Aphrodisias. In E. N. Zalta (Ed.), The Stanford Encyclopedia of Philosophy: URL = 
$<$ https://plato.stanford.edu/archives/win2017/entries/alexander-aphrodisias/>

Gaiser, K. (1968). Platons ungeschriebene Lehre. Stuttgart: Ernst Klett Verlag.

Gaiser, K. (1998). Testimonia Platonica. Le antiche testimonianze sulle dottrine non scritte di Platone. G. Reale \& V. Cicero, (Eds.). Milan: Vita e Pensiero.

Irwin, T. (1988). Aristotle's first principles. Oxford: Clarendon Press.

Isnardi-Parente, M. (1995). Analisi della testimonianza di Alessandro d'Afrodisia sul Perì tagathoû di Aristotele. Rendiconti dell'Accademia Nazionale dei Lincei, Series IX, Vol. VI, n. 1.

Isnardi-Parente, M. (2000). Alessandro d'Afrodisia e il Perì tagathoû di Aristotele. In A. Brancacci (Ed.), La filosofia in Età imperiale. Le scuole e le tradizioni filosofiche. Atti del Colloquio, Roma 17-19 giugno 1999 (pp. 245-270). Naples: Elenchos.

Kotwick, M. E. (2016). Alexander of Aphrodisias and the Text of Aristotle's Metaphysics. Berkeley: California Classical Studies.

Krämer, H. (1990). Plato and the foundations of metaphysics. A work on the theory of the principles and unwritten doctrines of Plato with a collection of the fundamental documents. J. R. Catan (Ed.). Albany: State University of New York Press.

Plato. (1997). Parmenides. In J. M. Cooper and D. S. Hutchinson (Eds.), Complete works (pp. 359-397). Indianapolis-Cambridge (MA): Hackett.

Reale, G. (1997). Toward a new interpretation of Plato. J. R. Catan \& R. Davies (Eds.). Washington, D.C.: The Catholic University of America Press.

Reale, G., \& Richard, M.-D. (2008). Platone: Dottrine non scritte (2 Vols.). Milan: Bompiani. 